\title{
A IMPORTÂNCIA DA ALIMENTAÇÃO SAUDÁVEL PARA O DESENVOLVIMENTO HUMANO
}

\author{
Gabriela Manhães Alves ${ }^{I}$ \& Teresa Claudina de Oliveira Cunha ${ }^{I}$
}

\begin{abstract}
RESUMO
ALVES, G. M.; CUNHA, T. C. O. A importância da alimentação saudável para o desenvolvimento humano. Perspectivas Online: Humanas \& Sociais Aplicadas, v.10, n.27, p.46 -62, 2020.

Neste trabalho procurou-se analisar os benefícios da alimentação saudável no desenvolvimento humano, para que assim, seja possível alcançar um ensinoaprendizagem/desenvolvimento com mais qualidade. Trata-se de um estudo de natureza aplicada, com uma abordagem com enfoque qualitativo. No decorrer da pesquisa, entrevistou-se uma nutricionista, uma professora de educação infantil e uma neuropsicopedagoga, com a finalidade de compreender por meio da teoria e práticas utilizadas em suas respectivas áreas, a importância da alimentação saudável como parte fundamental para o desenvolvimento

humano. A pesquisa possibilitou analisar a relação entre a alimentação e o desenvolvimento humano enquanto parceiros, em que a família e a escola são peças chaves na construção desse processo. Além disso, pode-se perceber que o papel/atuação do profissional da educação faz toda diferença neste processo, pois demanda um conhecimento sobre alimentação saudável, para que seja possível aplica-lo em suas práticas diárias no ambiente escolar, e assim, aos poucos ir construindo junto aos pais e alunos a concepção de que é preciso alimentar (cuidar) o corpo e também a mente.
\end{abstract}

Palavras-chave: Nutrição; Ensino-Aprendizagem; Infância. 


\begin{abstract}
In this paper we sought to analyze the benefits of healthy eating on human development, so that it is possible to achieve a higher quality teaching-learning / development. This is an applied study, with a qualitative approach. During the research, a nutritionist, a preschool teacher and a neuropsychopedagogue were interviewed, in order to understand through the theory and practices used in their respective areas, the importance of healthy eating as a fundamental part for human development. The research made it

between food and human development as partners, in which family and school are key pieces in the construction of this process. In addition, it can be seen that the role / performance of the education professional makes all the difference in this process, as it requires knowledge about healthy eating, so that it can be applied to their daily practices in the school environment, and thus to gradually build with parents and students the conception that it is necessary to feed (take care) the body and also the mind.
\end{abstract} possible to analyze the relationship

Keywords: Nutrition; Teaching and learning; Childhood.

\footnotetext{
${ }^{1}$ Institutos Superiores de Ensino do CENSA - ISECENSA - Laboratório de Formação de Professor - LAFORP - Rua Salvador Correa, 139, Centro, Campos dos Goytacazes, RJ, CEP: 28035-310, Brasil.

(*) e-mail: trcocunha@gmail.com

Data de recebimento: 15/02/2020. Aceito para publicação: 19/02/2020
}

Persp. Online: hum \& sociais aplicada., Campos dos Goytacazes, 27 (10) 46-62-2020 seer.perspectivasonline.com.br 


\section{INTRODUÇÃO}

O Ministério da Saúde (BRASIL, 2014) estabelece enquanto um direito humano básico, entre outras questões, a alimentação saudável, o que implica na

garantia ao acesso permanente e regular, de forma socialmente justa, a uma prática alimentar adequada aos aspectos biológicos e sociais do indivíduo e que deve estar em acordo com as necessidades alimentares especiais; ser referenciada pela cultura alimentar e pelas dimensões de gênero, raça e etnia; acessível do ponto de vista físico e financeiro; harmônica em quantidade e qualidade, atendendo aos princípios da variedade, equilíbrio, moderação e prazer; e baseada em práticas produtivas adequadas e sustentáveis.

Ainda segundo o Ministério da Saúde (2014) a alimentação vai além da ingestão de alimentos, pois

diz respeito à ingestão de nutrientes, mas também aos alimentos que contêm e fornecem os nutrientes, a como alimentos são combinados entre si e preparados, a características do modo de comer e às dimensões culturais e sociais das práticas alimentares. Todos esses aspectos influenciam a saúde e o bem-estar.

Segundo Oliveira (2017, p. 9) "é importante ressaltar como é essencial o envolvimento de políticas públicas voltadas para programas que contemplem estratégias e intervenções para ações direcionadas a promoção da saúde no âmbito escolar, respeitando o contexto sociocultural do aluno."

Na busca por atender ao que estabelece a Organização Mundial de Saúde (OMS) que indica que todos os países estabeleçam e atualizem sistematicamente "diretrizes nacionais sobre alimentação e nutrição, levando em conta mudanças nos hábitos alimentares e nas condições de saúde da população e o progresso no conhecimento científico" (BRASIL, 2014, p. 8), o governo brasileiro, por meio do Ministério da Saúde criou, em 2006 (autalizado em 2014), o "Guia Alimentar para a População Brasileira - Promovendo a Alimentação Saudável, instrumento que tem como objetivo "apoiar a educação alimentar e nutricional e subsidiar políticas e programas nacionais de alimentação e nutrição".

Este documento apresenta-se como

Um conjunto de estratégias que objetivam proporcionar aos indivíduos e coletividades a realização de práticas alimentares apropriadas. Essa diretriz também é uma prioridade na Política Nacional de Promoção da Saúde e, como tal, deve ser implementada pelos gestores e profissionais do Sistema Único de Saúde em parceria com atores de outros setores, privilegiando a participação popular (BRASIL, 2014, p. 9).

O Guia foi planejado para que seja utilizado em qualquer espaço, portanto,

nas casas das pessoas, nas unidades de saúde, nas escolas e em todo e qualquer espaço onde atividades de promoção da saúde tenham lugar, como centros comunitários, centros de referência de assistência social, sindicatos, centros de formação de trabalhadores e sedes de movimentos sociais (BRASIL, 2014, p. 11).

É preciso ver a alimentação como forma de garantir melhor qualidade de vida, e já que comer é um direito de todos, torna-se ato político, por isso não precisa e nem deve ser

Persp. Online: hum \& sociais aplicada., Campos dos Goytacazes, 27 (10) 46-62-2020 
complexo. Além disso, oferecer alimentos saudáveis no lugar de alimentos industrializados e processados é zelar também pela saúde.

A boa alimentação deve tornar-se, portanto, um hábito desde criança por toda a vida, pois é fundamental no desenvolvimento da criança, por isso é preciso conscientizar sobre os benefícios que nos trará desde a infância. Segundo o Ministério da Saúde (BRASIL, 2009) "a infância é um período em que se desenvolve grande parte das potencialidades humanas. Os distúrbios que incidem nessa época são responsáveis por graves consequências para indivíduos e comunidades". Uma alimentação equilibrada e saudável é fundamental no decorrer da infância, já que é nessa fase que acontece o desenvolvimento dos aspectos cognitivo, motor e afetivo da criança, por isso é uma fase muito importante que requer atenção e cuidados.

Cavalcanti et al. (2012), compreende a alimentação como uma das atividades humanas de maior relevância, não somente pelo caráter biológico, mas também por considerar que os aspectos sociais, psicológicos e econômicos são fundamentais para a evolução das sociedades. Para eles, a infância é fundamental para que o indivíduo posso adquirir hábitos alimentares saudáveis.

a alimentação desempenha um papel decisivo para o crescimento e o desenvolvimento físico da criança em idade escolar, época em que ela passa por um acelerado processo de maturação biológica, juntamente com o desenvolvimento socio psicomotor. Nesse contexto, a atuação da família e da comunidade são fundamentais (CAVALCANTI et al. 2012, p. 6).

Segundo Perroni (2013 apud OLIVEIRA, 2017, p. 13)

Tudo aquilo que ingerimos exerce um grande impacto sobre a função cerebral, podendo interferir no humor, no pensamento, no comportamento, na memória, no aprendizado e no envelhecimento celular. Através de uma alimentação colorida e variada, podemos fornecer os nutrientes necessários para manter o cérebro ativo e saudável.

$\mathrm{Na}$ esteira desse pensamento, Gomes (2016, p. 24) afirma que "o comportamento alimentar de uma criança reflete nos processos de crescimento e desenvolvimento em todos os aspectos. Com a devida atenção e cuidados pode-se promover uma maior expectativa de vida do adulto futuro".

Segundo o Ministério da Saúde (BRASIL, 2014), muitos são os mecanismos para seduzir e convencer os consumidores, principalmente crianças e adolescentes. $\mathrm{O}$ documento alerta a sociedade para o fato que de que $2 / 3$ dos anúncios de televisão que tratam da questão alimentação ressaltam, divulgam produtos industrializados, fastfoods, ultra processados lanches, bebidas e refeições prontas como refrigerantes, pizza, salsichas, hambúrgueres e outros.

O estudo e pesquisa apresentados pelo Ministério da Saúde ressalta para a importãncia de se apresentar e oferecer alimentos saudáveis para as crianças, a fim de que conheçam e aprendam desde cedo que é preciso haver um equilíbrio nutricional, compreendendo que todo ser humano precisa de nutrientes para garantir qualidade de vida.

\subsection{A alimentação saudável no âmbito escolar}

Persp. Online: hum \& sociais aplicada., Campos dos Goytacazes, 27 (10) 46-62-2020 
Segundo Oliveira (2017, p. 9) o sucesso escolar não pode ser considerado uma preocupação exclusiva da família e da escola, principalmente uma política pública. Para tanto, destaca que:

\begin{abstract}
O baixo índice de aprendizado, tem o levado a buscar por soluções, com intuito de aumentar o processo cognitivo no desempenho escolar. Sabendo que o aporte nutricional é essencial para execução de funções biológicas, a falta ou excesso desse, podem acarretar agravos a saúde de crianças e adolescentes e comprometer as funções cerebrais, provocando também, retardo no crescimento e na capacidade de aprendizado, dificuldades para desenvolvimento social, físico, psicológico e afetivo, além de apresentarem riscos para desenvolver doenças por déficit nutricionais.
\end{abstract}

Um dos fatores para que se possa conquistar uma alimentação saudável, é por meio de práticas educativas, que contribuem para construção de práticas alimentares satisfatórias (ZANCUL, 2008 apud RODRIGUES, 2018).

Para Accioly (2009 apud OLIVEIRA, 2017, p. 16) "o ambiente escolar faz parte do dia rotineiro da criança, local onde a convivência social, interação entre colegas, e este ambiente deve ser favorável para formação de hábitos saudáveis".

Gomes (2016) afirma ser o ambiente escolar um espaço propício para uma intervenção, na medida em que propicia além do desenvolvimento cognitivo, experiências significativas para a formação humana. Professores com uma estratégica pedagógica podem propor e criar receitas em sala de aula, envolvendo diretamente as crianças. Por meio do desenvolvimento de atividades lúdicas relacionadas a alimentação, pode-se esclarecer a resultado de uma alimentação inadequada, entre outros fatores.

Ao se falar sobre a relevância de uma alimentação saudável no ambiente escolar, não se pode restringir essa missão somente àqueles que trabalham neste meio, pois trata-se de uma questão envolve e demanda o auxílio da família e comunidade.

Segundo Freitas (2002 apud GOMES, 2017, p. 25),

a alimentação influi em nossa disposição, em nosso estado emocional e até nossa inteligência. Todo esse contexto pode prejudicar o interesse das crianças em frequentar a escola, apresentando baixo rendimento, irritabilidade, agitação, estresse, apatia dentre outros.

Oliveira (2017, p. 17) ressalta sobra a existência de estudos e pesquisas que indicam a relação entre a boa alimentação e a atividade cerebral. Que a ausência de nutrientes pode ocasionar também "problemas comportamentais, como comportamento antissocial, estreitamento das relações com os colegas de sala, podendo atingir o alto estima e atenção, diminuir a motivação provocar estresse e ansiedade fora do normal e ainda depressão". Segundo o autor, todos esses fatores podem comprometer o funcionamento cognitivo e gerar o fracasso escolar. A desnutrição decorrente da infầncia, mesmo que moderada, apresenta-se como uma das principais responsáveis por problemas no desenvolvimento mental e no desempenho escolar.

Percebe-se, portanto, que uma ausência ou uma alimentação inadequada pode ser responsável pela diminuição das capacidades de um indivíduo para realizar atividades cotidianas. A desnutrição pode gerar sequelas muitas vezes irreversíveis no desenvolvimento físico, mental, cognitivo e psicossocial de um indivíduo. Uma alimentação adequada ativa o cérebro, assim como proporciona o bem estar integral de uma criança. Importante se faz,

Persp. Online: hum \& sociais aplicada., Campos dos Goytacazes, 27 (10) 46-62-2020 
portanto, que a escola tenha conhecimento da realidade anterior da criança para possa, em conjunto com a família, buscar recursos para eliminar as dificuldades que possam estar sendo responsáveis pela não participação da criança nas atividades educacionais.

\title{
1.2. Influência da Família na alimentação da criança
}

Para o Estatuto da Criança e do Adolescente - ECA (1990), "o desenvolvimento infantil vai muito além dos cuidados de saúde, pois a criança necessita de estímulos para desenvolver habilidade social, cognitiva e emocional" (BRASIL, 2005 apud OLIVEIRA, 2017, p. 14).

A família é fundamental no processo de alimentação da criança. Segundo o Ministério da Saúde (BRASIL, 2014, p.118),

\begin{abstract}
As crianças estão em um processo especial de desenvolvimento e, sozinhas, ainda não conseguem compreender muitos dos elementos do mundo adulto. Cada vez mais precocemente, as crianças se constituem no público-alvo da publicidade de alimentos. Isso por conta da influência que exercem na escolha das compras das famílias e também porque estão formando hábitos de consumo que poderão prolongar-se pelo resto de suas vidas.
\end{abstract}

Ramos e Stein (2000 apud OLIVEIRA, 2017, p. 16), "afirmam também que entre os fatores inter-relacionados na aquisição do comportamento alimentar infantil, ressaltam-se os psicossociais, responsáveis pela transmissão da cultura alimentar e aqui examinados sob a perspectiva familiar".

Segundo o Guia Alimentar para a População Brasileira (BRASIL, 2014), conhecer novos alimentos cria bons hábitos de alimentação, além de valorizar que a criança participe do processo de preparação das refeições. Para tanto, torna-se fundamental a participação família nas atividades de planejar, adquirir, preparar e servir os alimentos. Outro ponto de destaque, diz respeito ao envolvimento de crianças e adolescentes na aquisição de alimentos e no preparo de refeições possibilita o conhecimento de diferentes alimentos e de novas maneiras de prepará-los.

Encontra-se, ainda, no referido documento que:

A vida moderna é marcada por crescentes demandas e pela falta crônica de tempo, e essas circunstâncias hoje são comuns a homens e mulheres. O compartilhamento de responsabilidades no processo doméstico envolvido com a preparação de refeições e a divisão das tarefas entre todos, incluindo homens e mulheres e crianças e adolescentes, são essenciais para que a carga de trabalho não pese de modo desproporcional sobre um dos membros da família (BRASIL, 2014, p. 98).

Para Oliveira (2017, p. 16),

Durante a infância é muito importante que a família, os educadores e todos que estão ao seu redor possam compartilhar com a criança informações sobre as suas escolhas alimentares, pois nessa fase não são dotas de conhecimento sobre os valores nutricionais dos alimentos, elas aprendem através de observação no meio que a mesma vivi e os hábitos são transferidos através dos familiares.

Sendo assim, no cotidiano familiar, a participação dos pais é de grande importância para promover a alimentação saudável da criança. Para Santos (1989 apud GOMES, 2016, p. 23) 
Os pais tem grande responsabilidade na alimentação da criança cabe a eles a levar as crianças preferir alimentos saudáveis, indispensáveis ao seu desenvolvimento, esta tarefa não é feita só com palavras, sobretudo com exemplos, a criança deve compreender que comer bem não significa comer muito, nem comer apenas coisas gostosas, mas alimentar-se adequadamente e de forma equilibrada.

Os autores aqui citados reforçam, portanto, que apesar da falta de tempo e da influência das mídias a todo o momento, a família precisa estar atenta aos alimentos que põe na mesa, pois é principalmente por meio dela que a criança será influenciada a experimentar alimentos saudáveis, criando assim um hábito saudável que irá perdurar para o resto da vida, trazendo todos os benefícios necessários para seu pleno desenvolvimento.

A proposta desse estudo é principalmente analisar os benefícios e riscos que a alimentação saudável pode trazer para o desenvolvimento humano, buscando melhor rendimento cognitivo e uma aprendizagem mais significativa. Assim como, identificar os benefícios e riscos da alimentação saudável com interferência no ensino aprendizagem; investigar a importância da orientação/conscientização da alimentação saudável aos alunos no âmbito escolar e também de seus pais e responsáveis; apresentar a importância a alimentação saudável para saber trabalhar de forma interdisciplinar.

\title{
2. METODOLOGIA
}

Este estudo de natureza aplicada, quanto a abordagem teve um enfoque qualitativo. Segundo Hernández Sampieri (2013, p. 33), "as pesquisas qualitativas se baseiam mais em uma lógica e em um processo indutivo (explorar e descrever, e depois gerar perspectivas teóricas). Vão do particular ao geral” p. 26):

Quanto aos objetivos foi de natureza exploratória e descritiva. Segundo Santos (2001,

\begin{abstract}
Após a primeira aproximação (pesquisa exploratória), o interesse é descrever um fato ou fenômeno. Por isso a pesquisa descritiva é o levantamento das características conhecidas, componentes do fato/fenômeno/problema. É normalmente feita a forma de levantamentos ou observações sistemáticas do fato/fenômeno/problema.
\end{abstract}

Com relação aos procedimentos técnicos foram utilizados a pesquisa bibliográfica e de campo. Para a coleta de dados utilizou-se da entrevista com roteiro estruturado, com uma pauta definida com os profissionais - Nutricionista, Professora Educação Infantil e Neuropsicopedagoga. A entrevista possibilitou a coleta de dados subjetivos, assim como a compreensão da realidade.

\section{RESULTADOS E DISCUSSÃO}

A pesquisa envolveu a participação de 03 (três) profissionais de áreas distintas: uma nutricionista com atuação há oito anos em uma instituição de ensino, onde são preparados e servidos 3.850 refeições por dia; uma professora que atua na educação infantil há cerca de 5 anos (a opção por esse profissional justifica-se por realizar em seu dia a dia atividades que envolvem a alimentação saudável, além de atividades de conscientização propriamente voltadas para o tema); e por fim, a última entrevista foi realizada com uma neuropsicopedagoga, com atuação em uma clínica de psicopedagogia.

Persp. Online: hum \& sociais aplicada., Campos dos Goytacazes, 27 (10) 46-62-2020 
O que essas três áreas têm em comum? O desenvolvimento humano. Na pesquisa em questão, um ponto fundamental é a relação entre alimentação saudável e o desenvolvimento humano.

Segundo os artigos 10 e 16 da Resolução Sociedade Brasileira de Neuropsicopedagogia $n^{\circ} 03 / 2014$ :

Art. 10. A Neuropsicopedagogia é uma ciência transdisciplinar, fundamentada nos conhecimentos da Neurociências aplicada à educação, com interfaces da Pedagogia e Psicologia Cognitiva que tem como objeto formal de estudo a relação entre o funcionamento do sistema nervoso e a aprendizagem humana numa perspectiva de reintegração pessoal, social e educacional.

Artigo 16. O Neuropsicopedagogo deve ter como princípio básico a promoção do desenvolvimento das pessoas que o recorrem sob seu atendimento profissional devendo utilizar todos os recursos técnicos disponíveis (principalmente a transdisciplinaridade) e de acordo com cada especificidade, proporcionando o melhor serviço possível.

A Resolução do Conselho Nacional de Educação/Conselho de Ensino Superior $n^{\circ}$ 5/2001 estabelece o perfil do profissional de Nutrição:

Nutricionista, com formação generalista, humanista e crítica, capacitado a atuar, visando à segurança alimentar e à atenção dietética, em todas as áreas do conhecimento em que alimentação e nutrição se apresentem fundamentais para a promoção, manutenção e recuperação da saúde e para a prevenção de doenças de indivíduos ou grupos populacionais, contribuindo para a melhoria da qualidade de vida, pautado em princípios éticos, com reflexão sobre a realidade econômica, política, social e cultural.

Para Sonati (2009, p. 32) "a ciência da nutrição, juntamente com os profissionais da educação, pode colaborar com a formação de hábitos saudáveis de alimentação nas crianças do ensino público e particular".

Portanto, na área da neuropsicopedagogia e da nutrição, é possível compreender por meio da teoria, que as duas áreas têm um papel fundamental para o desenvolvimento de um indivíduo, e, a importância da conscientização e orientação da alimentação saudável desde a infância. Na área da educação, a partir da prática da professora de educação infantil, foi possível compreender como é importante, trabalhar a alimentação de forma direta e indiretamente em sala de aula.

\subsection{Da Alimentação Saudável na Escola}

A partir da entrevista com a neuropsicopedagoga "M. L. M. G." pode-se perceber a importância da relação entre uma rotina de alimentação saudável com os processos de aprendizagem na educação, quando esta afirma que:

\footnotetext{
“A integridade dos neurônios é responsável pelas sinapses necessárias à atuação do indivíduo em todas as áreas necessárias a uma vida saudável. A alimentação é um dos fatores imprescindíveis para que os neurônios podem estar íntegros o suficiente para que as sinapses aconteçam e os neurotransmissores respondam de forma significativa e positiva no desenvolvimento global do indivíduo. Ouso dizer que o grande índice de pessoas com depressão deve-se, além de questões afetivas, a uma alimentação inadequada e restrita devido a dietas constantes. Sem alimentação adequada, os neurotransmissores responsáveis pelo prazer, alegria ficam comprometidos e então são necessárias intervenções químicas (medicações) para fazer a recapitação desses neurotransmissores".
}

Persp. Online: hum \& sociais aplicada., Campos dos Goytacazes, 27 (10) 46-62-2020 
Um profissional preocupado, portanto, com o desenvolvimento de seu aluno, deve buscar todas as formas possíveis de potencializar esse desenvolvimento. A alimentação, muitas vezes "esquecida" como parte desse processo é de suma importância.

Ainda segundo a Neuropsicopedagoga: "há pesquisas que apontam alimentos que podem prejudicar ou auxiliar o processo de aprendizagem. As crianças com transtornos de aprendizagem, por exemplo, como Déficit de Atenção e hiperatividade não devem ingerir alimentos que excitam". Ao dizer isso, citou exemplos como "Coca-Cola, Guaraná, e outros alimentos que contém cafeína que podem excitar e potencializar a hiperatividade". E, completou, afirmando que por outro lado, existem alimentos que contém Ômega 3, como peixes, que auxiliam na atenção e memória.

Para Lacerda e Accioly (2002 apud Fernandes, 2010), a alimentação é fundamental em todos os ciclos da vida, no entanto na fase da educação infantil afetará decisivamente na adolescência e vida adulta

A partir de fragmentos de falas da nutricionista "A. A." pode-se perceber o quanto uma boa alimentação influencia no bem-estar do indivíduo. A profissional destacou, contudo, que a alimentação deve ser equilibrada, mais balanceada, sempre buscando o mínimo de alimentos processados.

O estudo buscou também compreender como o assunto Alimentação Saudável está presente no cotidiano das escolas. Questionadas se o assunto/tema Alimentação Saudável deve ser abordado em sala de aula, pode-se agrupar as afirmações:

\begin{abstract}
"A escola em que atuo demonstra a preocupação com a orientação/conscientização das crianças para com hábitos saudáveis de alimentação. Disponibiliza uma sugestão de um cardápio saudável para cada dia da semana e também estamos desenvolvendo um projeto, cujo tema será: 'Menos industrializados e mais orgânicos', ressaltando sobre a importância do plantar para consumir e eles estão participando de todo o processo". (Depoimento da Professora A. L. B.)
\end{abstract}

\begin{abstract}
"Quanto mais cedo eles aprenderem os benefícios que uma alimentação adequada às necessidades deles pode trazer, mais chances teremos de ter no futuro indivíduos saudáveis. E mais chance desse aprendizado se propagar. O estudante aprende também por repetição. Por hábito. É preciso criar o bom hábito". (Depoimento da Nutricionista A. A.)

"A educação para uma alimentação saudável deve fazer parte do currículo nas escolas que atuam com crianças e adolescentes, principalmente. A orientação alimentar na escola tem trazido grandes benefícios para a aprendizagem porque, na esteira desse processo, há também uma orientação familiar para a mudança de hábitos alimentares equivocados". (Depoimento da Neuropsicopedagoga M. L. M. G.)
\end{abstract}

Percebe-se, portanto, que o fator alimentação apresenta-se como de relevância para o desenvolvimento humano. Deve-se destacar ainda, que este não deve ser "privilégio" de uma ou outra escola, mas um assunto a ser abordado e trabalhado em todas escolas, na medida em que é uma questão de saúde pública. A definição de alimentação saudável está prevista na Política Nacional de Alimentação e Nutrição (2007):

Alimentação adequada e saudável é uma prática alimentar apropriada aos aspectos biológicos e socioculturais dos indivíduos, bem como ao uso sustentável do meio ambiente. Deve estar de acordo com as necessidades de cada fase do curso da vida e

Persp. Online: hum \& sociais aplicada., Campos dos Goytacazes, 27 (10) 46-62-2020 
com as necessidades alimentares especiais; ser referenciada pela cultura alimentar e pelas dimensões de gênero, raça e etnia; ser acessível do ponto de vista físico e financeiro; harmônica em quantidade e qualidade; baseada em práticas produtivas adequadas e sustentáveis; com quantidades mínimas de contaminantes físicos, químicos e biológicos”. (BRASIL, UNICEF, 2019, p. 7).

Para a UNICEF a compreensão do que representa alimentação saudável se faz imprescindível para o desenvolvimento integral do ser humano.

Alimentar-se bem vai muito além de receber os nutrientes que vão manter o nosso corpo. O modo como você come e aspectos como idade, gênero, cultura, forma de preparação e origem dos alimentos, a relação com o meio ambiente, preço, disponibilidade dos alimentos perto de sua casa, equilíbrio entre qualidade e quantidade e o prazer de comer também são levados em consideração no conceito de Alimentação Saudável e estão previstos na Política Nacional de Alimentação e Nutrição.

O direito à alimentação saudável se apresenta, portanto, como objeto de preocupação de vários órgãos oficiais no Brasil e que se faz necessário ser trazido à reflexão para o interior das escolas e discutido em conjunto educadores e família.

\subsection{Alimentação e a Didática}

Prosseguindo à análise, buscou-se identificar quais estratégias podem ser desenvolvidas na sala de aula:

Quadro 1: Das estratégias de ensino para abordar o assunto/tema Alimentação Saudável em sala de aula. Fonte: Pesquisa própria.

\begin{tabular}{|l|l|}
\hline Profissionais & Estratégias \\
\hline Neuropsicopedagoga & $\begin{array}{l}\text { 1- Levar para sala de aula alimentos que se classificam como } \\
\text { saudáveis e não saudáveis. } \\
2-\text { Visita a supermercados para observação de aquisição de } \\
\text { alimentos saudáveis. } \\
\text { 3- Levar para a escola um profissional de nutrição para } \\
\text { conversa com crianças e esclarecimento sobre uma boa } \\
\text { alimentação. }\end{array}$ \\
\hline Professora (Figura 1) & $\begin{array}{l}\text { Que as crianças sintam a textura e o gosto do alimento, não } \\
\text { tendo pressa pois ela pode não gostar de primeira, mas com o } \\
\text { costume ao experimentar ela vai gostar; } \\
\text { 2- Cardápio sugestivo; } \\
\text { 3- Pratos coloridos, lúdicos e nutritivos (construir imagens com } \\
\text { as frutas). }\end{array}$ \\
\hline
\end{tabular}

Persp. Online: hum \& sociais aplicada., Campos dos Goytacazes, 27 (10) 46-62-2020 seer.perspectivasonline.com.br 


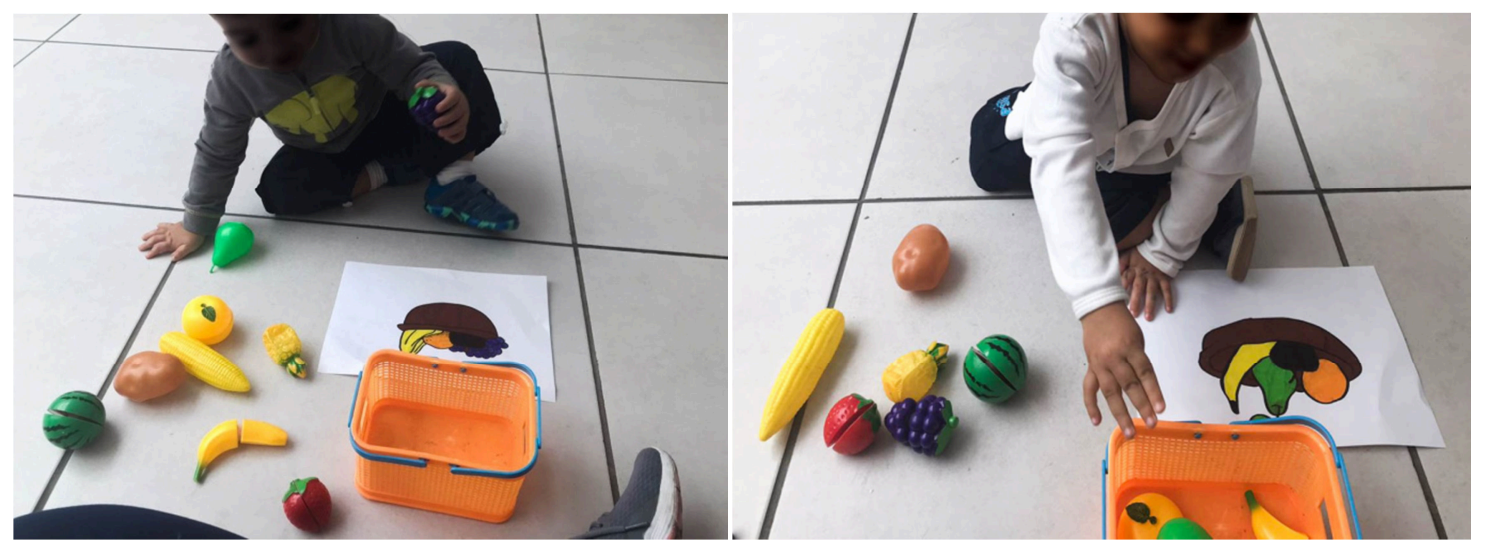

Figura 1: Atividade: comparação do desenho x realidade.

Fonte: Pesquisa de campo própria.

Para a nutricionista, optou-se por perguntar se esta considera importante que o assunto/tema Alimentação Saudável seja abordado em sala de aula.

"Entendemos que nos dias atuais a vida familiar tem sido corrida ou ausente. Isso aumenta o papel da escola. Hoje não só ensinamos matemática, português e outras disciplinas, como precisamos estar atentos a todo âmbito educacional. Como eu disse, o aluno aprende também por repetição. Se ele ouve em casa o que é alimentação saudável, na tv, nas redes sociais, ele aprende mais. E é na escola que ele passa o maior tempo do dia (nossos alunos são do integrado)" (Depoimento da Nutricionista A. A.)

Sobre essa questão, pode-se observar uma concordância da professora “A. L. B.” a partir da fala:

"Com a correria do dia a dia, até nós estamos mais "prováveis" a consumir alimentos industrializados e é preciso que a escola conscientize aos pais e alunos a importância de uma alimentação saudável".
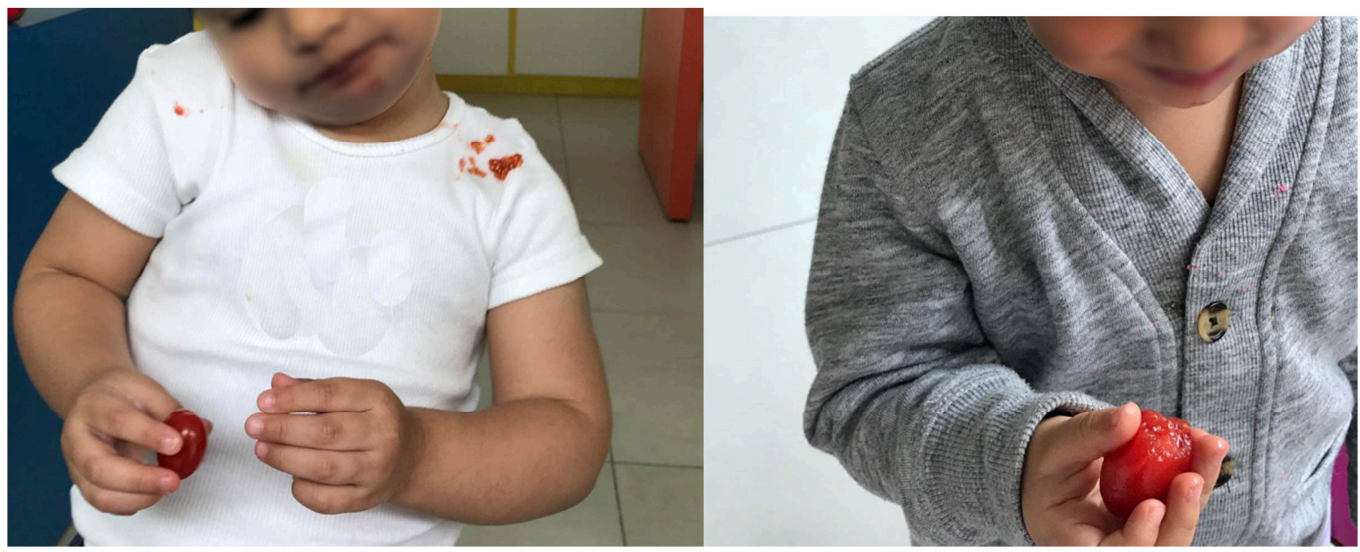

Figura 2: Atividade "Explorando as frutas - Atividade Sensorial" Fonte: Pesquisa de Campo própria.

A Figura 2 mostra uma atividade desenvolvida pela professora A.L.B em sala de aula, como a finalidade de trabalhar as frutas de forma lúdica explorando os sentidos. Com esta atividades lúdica a professora buscou trabalhar os diferentes tipos, cores, formas e sabores de frutas por meio da temática dos sentidos. 
Pode-se observar que muitas crianças desconheciam não só o sabor, mas as frutas e os seus nomes, mesmo sendo algumas frutas comuns, do cotidiano.

Ao ser questionada, a nutricionista "A. A." disse que a má alimentação pode interferir no rendimento escolar e físico, na medida em que uma mente mal nutrida, não conseguirá focar e compreender o que está sendo dado em sala de aula e que nessas condições o aluno pode ficar indisposto, sentir dor de cabeça e dessa forma não há como sustentar a atenção.

Para Fernandes (2010, p. 11) não se pode ignorar que alguém em estado de desnutrição não apresente resistência quanto a realização de qualquer atividade proposta. Para o autor, "ninguém pode trabalhar com fome. A criança de 3 a 5 anos não consegue exercer com eficiência a atividade com fome".

Oliveira (2007 apud FERNANDES, 2010, p. 22) destaca também que:

\begin{abstract}
A falta de informação tem sido um dos grandes obstáculos na prevenção de inúmeras doenças que tem assolado de forma impiedosa a nossa sociedade. Bombardeada pelas inúmeras propagandas, as pessoas não dão importância a composição, absorção e assimilação das substâncias alimentares, não sabendo selecionar os alimentos, preferindo frequentemente os que não são saudáveis.
\end{abstract}

Sendo assim, é preciso não apenas saber sobre a importância da alimentação saudável no desenvolvimento humano, um profissional que trabalha com desenvolvimento de pessoas deve conhecer e saber trabalhar com a alimentação, principalmente na área da educação, buscando assim desenvolver ao máximo o seu aluno.

Dando continuidade à pesquisa, ao ser questionada sobre a possibilidade de melhorar o rendimento do cérebro fornecendo determinados nutrientes, a Neuropsicopedagoga discorre que "é comprovado cientificamente que há alimentos que podem potencializar a capacidade do indivíduo para a atenção e memória, elementos indispensáveis à aprendizagem".
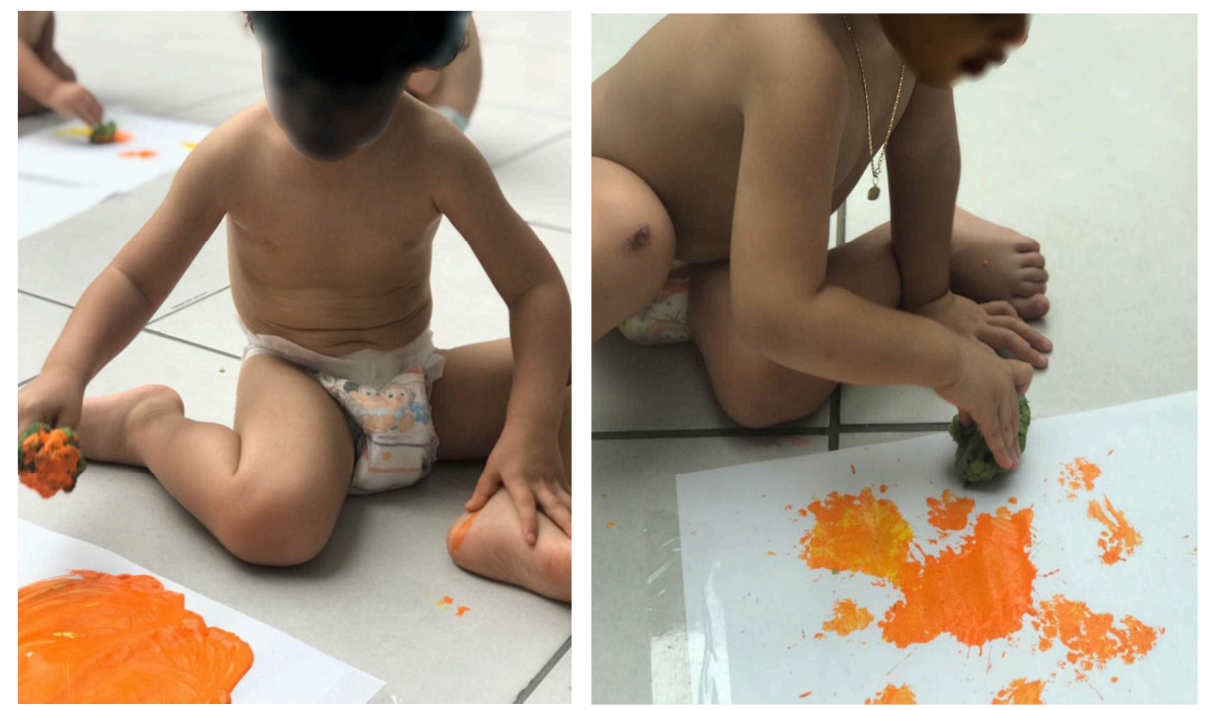

Figura 3: Trabalhando Vegetais: carimbos divertidos.

Fonte: Pesquisa de Campo própria.

A Figura 3 mostra uma atividade realizada em sala de aula, onde buscou-se trabalhar as formas através de vegetais utilizando-os como "carimbos divertidos". Percebe-se, portanto, que o saber trabalhar com alimentação saudável não envolve somente a relação professoraluno, na medida em que ao se questionar a professora sobre as dificuldades encontradas para

Persp. Online: hum \& sociais aplicada., Campos dos Goytacazes, 27 (10) 46-62-2020 
realizar o trabalho de orientação/conscientização para uma alimentação saudável, a mesma afirmou que nem todos os pais reconhecem a importância da atividade, o que acaba gerando a falta de colaboração dos pais em desenvolver o trabalho.

\subsection{Família e Escola}

A partir do aporte teórico pode-se compreender que a relação família-escola é possível construir desde a infância uma cultura de alimentação saudável. Para a professora, a criança também deve ser estimulada em casa, assim como seus familiares também precisam ter esses hábitos alimentares.

Para Gaglione (2003 apud SILVA, 2003 p. 17) o comportamento dos pais influencia o hábito alimentar de seus filhos, portanto, "os pais devem adotar hábitos que gostariam de ver em seus filhos".

$\mathrm{Na}$ esteira desse pensamento, a Nutricionista destaca ainda que "vem de casa o maior aprendizado. A família é peça fundamental para divulgar e persistir nessa missão." Portanto abordar o tema/assunto Alimentação Saudável na sala de aula é importante, mas também deve-se conscientizar os pais e responsáveis.

Perguntada se a escola em que atua tem uma preocupação em orientar/conscientizar a família para a importância da alimentação saudável, a professora "A. L. B." afirmou que sim, e que para isso, a escola disponibiliza um cardápio saudável sugestivo, além de proporcionar oficinas, cujo objetivo é a de construir "pratinhos" saudáveis. Informou que, nesse momento, pais e responsáveis podem participar com as crianças.
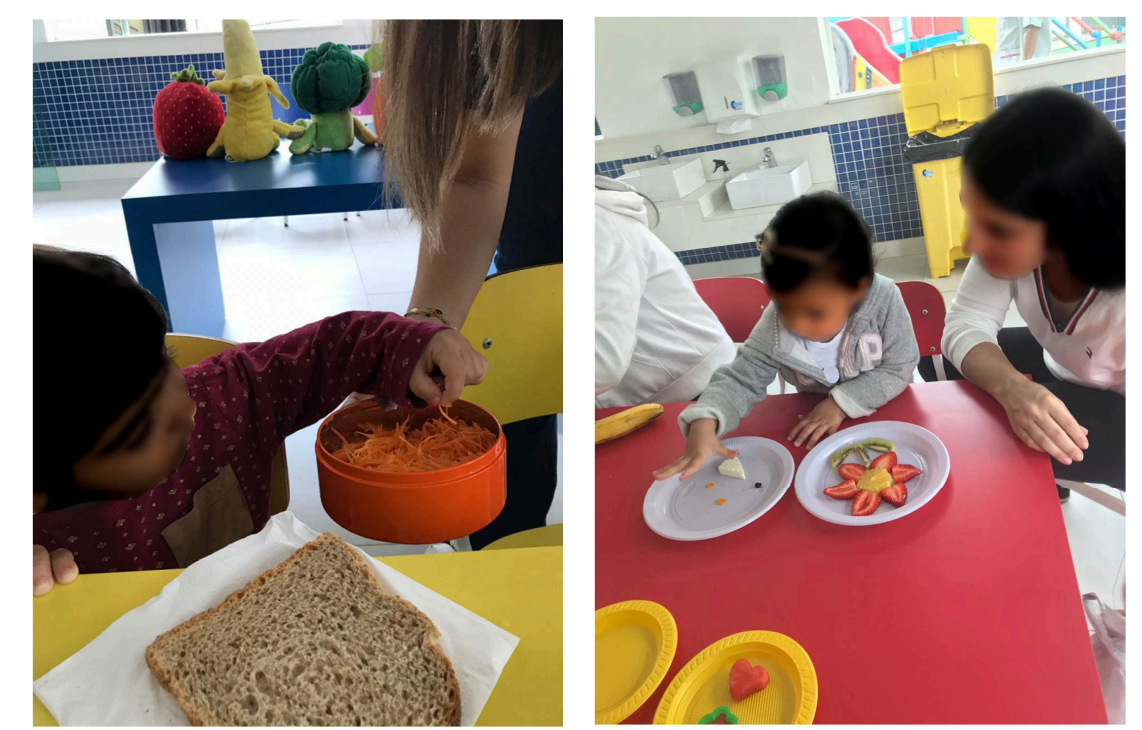

Figura 4: Oficina de pratos saudáveis com participação de alunos e pais ou responsáveis.

Fonte: Pesquisa de Campo própria.

Na Figura 4 tem-se um exemplo de uma ação implementada pela Escola em que se teve a parceria com a família. A ação incentivou a criança a montar o seu próprio "lanchinho" saudável de forma divertida, cheia de cores. Esse trabalho teve a participação direta dos pais ou responsáveis.

O comportamento alimentar no pré-escolar é determinado, em primeira instância, pela família da qual ela é dependente e, secundariamente, pelas outras interações

Persp. Online: hum \& sociais aplicada., Campos dos Goytacazes, 27 (10) 46-62-2020 seer.perspectivasonline.com.br 
psicossociais e culturais da criança. Assim, os alimentos que os indivíduos consomem rotineiramente e repetidamente, no seu quotidiano caracterizam o seu hábito ou comportamento alimentar (FERNANDES, 2010, p. 22).

Nem tudo é tão simples e fácil como parece, existem dificuldades que os pais encontram na hora de manter uma alimentação saudável em casa, a Nutricionista "A. A." cita alguns exemplos como: "poder econômico, dia a dia corrido, distância entre trabalho x casa $\mathrm{x}$ escola. Algumas vezes o não conhecimento, a não orientação do que se deve ou não fazer."

\begin{abstract}
“Uma criança obesa, será um adulto obeso. É na infância que suas células estão em formação e multiplicação. Uma criança não sabe o que e certo ou errado, bom ou ruim. Ela vai aceitar aquilo que derem a ela como certo ou como bom. Criar bons hábitos não é fácil. Dá trabalho. Requer paciência, persistência. Mas os frutos que serão colhidos, serão pra vida toda.” (Depoimento da Nutricionista)
\end{abstract}

Finalizando a pesquisa, buscou identificar se alimentação pode interferir no rendimento escolar e físico. Para a neuropsicopedagoga "M. L. M. G.”:

\begin{abstract}
“A alimentação corresponde a um poderoso aspecto da saúde humana. A má alimentação ou um hábito alimentar equivocado vai impactar sobremaneira no desenvolvimento global do indivíduo. Um dos aspectos importantes da má alimentação é a questão estética, pois crianças e adolescentes que estão acima do peso, além de terem prejuízos no desempenho escolar, por ficarem mais lentos e sonolentos, acabam por serem vítimas de bullying nas escolas e isso traz consequências seríssimas para sua autoestima e, consequentemente, para seu desempenho escolar. Não raro encontramos crianças ou adolescentes que apresentam desempenho escolar abaixo da média e não possuem qualquer transtorno que justifique esse quadro. A causa está muitas vezes no sofrimento trazido pela não aceitação de seu corpo e essa é uma questão séria que precisa ser tratada quando se fala de alimentação e aprendizagem".
\end{abstract}

Para a Professora “A. L. B.”, a alimentação pode interferir no rendimento, atrapalhando na concentração, raciocínio, assim como a obesidade infantil. Sobre a obesidade a Nutricionista "A. A." disse que:

"O dia a dia corrido aumentou em muito a ingestão de alimentos processados. Consumo de doces em excesso (refrigerantes por exemplo). A praticidade de se abrir um pacote ao invés de preparar seu alimento, seu suco, seu lanche, trouxe muitos problemas alimentares. E a falta de atividade física. Hoje às crianças brincam dentro de casa, nos seus celulares e videogames. O sedentarismo aliado a má alimentação são os maiores vilões".

A Nutricionista disse que além do fator obesidade, a má alimentação pode oferecer também muitos riscos aos jovens e adolescentes como "diabetes, colesterol alto, hipertensão arterial sistêmica (pressão alta), anemia, problemas cardíacos, ósseos, baixo desenvolvimento cognitivo, e até problemas neurológicos". Segundo a Nutricionista deve-se "aprender a se alimentar de forma equilibrada. Com ingestão de alimentos in natura ou minimamente processados. Sem excessos. De açúcar, de sal, de gorduras. Alimentação variada em cor, sabor, texturas. E também a realização de atividades físicas", são práticas que podem ser realizadas a fim de evitar males no futuro.

Portanto, além de sua importância no desenvolvimento escolar, a alimentação saudável merece uma maior atenção, na medida em que pode ser considerada uma aliada na prevenção e tratamento de doenças. Por isso, a Organização Mundial da saúde (1946) afirma que "a saúde é um estado de completo bem-estar físico, mental e social, e não consiste apenas na ausência de doença ou de enfermidade" e que "o desenvolvimento saudável da criança é de

Persp. Online: hum \& sociais aplicada., Campos dos Goytacazes, 27 (10) 46-62-2020 
importância basilar; a aptidão para viver harmoniosamente num meio variável é essencial a tal desenvolvimento".

\section{CONSIDERAÇÕES FINAIS}

O desenvolvimento desta pesquisa possibilitou a análise da alimentação saudável como aliada ao desenvolvimento humano. A família e a escola aparecem como grandes protagonistas nesse processo, na medida em que o trabalho conjunto traz a possibilidade de criar uma cultura de hábitos alimentares saudáveis, em que é possível obter resultados significativos de aprendizagem, assim como uma boa memória, concentração e disposição. As vozes presentes neste estudo está caracterizada pelo depoimento de profissionais que atuam direta ou indiretamente com a questão alimentação saudável e desenvolvimento escolar.

O professor preocupado com o desenvolvimento de pessoas/alunos, deve procurar formas possíveis de atingir o desenvolvimento integral do aluno. Para tanto, compreender que alimentação saudável é fundamental como parte desse processo, demanda a busca para um aprendizado maior sobre o assunto para que se possa também ensinar e aplicar a alimentação saudável nas práticas diárias no ambiente escolar.

A pesquisa revela que, criar uma rotina de alimentação saudável faz bem para o indivíduo, de forma física e também mental, tornando-se um grande aliado no desenvolvimento humano, principalmente na infância em que as janelas da aprendizagem estão abertas, prontas para receberem mais e mais informações. Não se trata apenas de comer, e sim, alimentar o corpo e também a mente.

Neste estudo não se pretende fechar uma questão, mas possibilitar uma reflexão sobre a importância da alimentação saudável para o desenvolvimento humano. Acredita-se ser importante a continuidade desse estudo envolvendo também pais ou responsáveis.

\section{REFERÊNCIAS}

BRASIL. Diretrizes Curriculares Nacionais do Curso de Graduação em Nutrição. Resolução CNE/CES No 5, de 07 de novembro de 2001. Institui Diretrizes Curriculares Nacionais do Curso de Graduação em Nutrição. Disponível em: http://www.abmes.org.br/arquivos/ legislacoes/res_ces_cne_05_071101.pdf. Acesso em: 16 nov. 2019.

BRASIL. Ministério da Saúde. Secretaria de Atenção à Saúde. Departamento de Atenção Básica. Guia alimentar para a população brasileira. 2. ed., 1. reimpr. - Brasília: Ministério da Saúde, 2014. Disponível em: http://bvsms.saude.gov.br/bvs/publicacoes/guia_alimentar_populacao_brasileira_2ed.pdf. Acesso em: 20 abr. 2019.

BRASIL. Ministério da Saúde. Secretaria de Atenção à Saúde. Departamento de Atenção Básica. Política nacional de alimentação e nutrição. 2. ed. rev. - Brasília: Ministério da Saúde, 2007. Disponível em: https://conselho.saude.gov.br/biblioteca/livros/politica alimentacao_nutrição .pdf. Acesso em: 04 dez. 2019.

BRASIL. Ministério da Saúde. Secretaria de Atenção à Saúde. Departamento de Atenção Básica. Saúde da criança: nutrição infantil: aleitamento materno e alimentação complementar / Brasília : Editora do Ministério da Saúde, 2009. 112 p. (Série A. Normas e Manuais Técnicos) (Cadernos de Atenção Básica, n. 23). Disponível em:

Persp. Online: hum \& sociais aplicada., Campos dos Goytacazes, 27 (10) 46-62-2020 
http://dms.ufpel.edu.br/ares/bitstream/handle/123456789/61/saúde_crianca_nutricao_aleitame nto_alimentacao.pdf? sequence=1. Acesso em: 20 abr. 2019.

BRASIL. Fundo das Nações Unidas para a Infância UNICEF. Comer bem e melhor: dicas para promover alimentação saudável entre crianças e adolescentes. Brasília: UNICEF, 2019. Disponível em: https:/www.unicef.org/brazil/media/1101/file/Comer _bem_e_melhor.pdf. Acesso em: 04 dez. 2019.

CAVALCANTI, L. A. et al. Efeitos de uma intervenção em escolares do ensino fundamental 1, para a promoção de hábitos alimentares saudáveis. Revista Brasileira de Ciência e Movimento, v. 20, n. 2, p. 5-13, 2012. Disponível em: https://portalrevistas.ucb.br/ index.php/RBCM/article/view/2408/2247. Acesso em: 02 jun. 2019.

CONSTITUIÇÃO DA ORGANIZAÇÃO MUNDIAL DA SAÚDE (OMS/WHO), 1946. Disponível em: http://www.direitoshumanos.usp.br/index.php/OMS-Organiza\%C3\%A7\%C3 $\%$ A3o-Mundial-da-Sa\%C3\%BAde/constituicao-da-organizacao-mundial-da-saudeomswho.html. Acesso em: 11 nov. 2019.

FERNANDES, E. A. V. O Papel da alimentação no desenvolvimento da criança: estudo de caso Jardim Sorriso. 2010. Universidade de cabo verde, Cabo verde, 2010 Disponível em: http://www.portaldoconhecimento.gov.cv/bitstream/10961/2119/1/Monograf EurisaV0.pdf. Acesso em: 23 out. 2019.

GOMES, W. S. T. Alimentação escolar saudável. 2016. Trabalho de Conclusão de Curso (Licenciatura em Educação do Campo) - Universidade de Brasília - UnB, Brasília, 2016. Disponível em: http://www.bdm.unb.br/bitstream/10483/16720/1/2016_WednaTeixeira Gomes_tcc.pdf. Acesso em 16. Jun. 2019.

HERNÁNDEZ SAMPIERI, R.; COLladO, C. F.; LUCIO, M. P. B. Metodologia de pesquisa. Tradução por Daisy Vaz de Moraes. 5. ed. Porto Alegre: Penso, 2013.

OLIVEIRA, B. S. Influência da alimentação no desempenho escolar de crianças e adolescentes. 2017, 30 p. Trabalho de Conclusão de Curso (Bacharelado em Nutrição). União Metropolitana de Educação e Cultura- (UNIME). 2017. Disponível em: https://repositorio.pgsskroton.com.br/bitstream/123456789/15099/1/BRUNA\%20

SANTANA\%20OLIVEIRA.pdf. Acesso em: 02 jun. 2019.

RIBEIRO, G. N. M.; SILVA, J. B. L. A alimentação no processo de aprendizagem. Revista Eventos Pedagógicos, v. 4, n. 2, p. 77-85, ago.-dez. 2013. Disponível em: http://sinop.unemat.br/projetos/revista/index.php/eventos/article/ download /1270/941. Acesso em: 24 maio 2019.

RODRIGUES, R.M. S. N. Abordagem da educação alimentar e nutricional no contexto escolar através do Parâmetros Curriculares Nacionais (PCNs) transversal de saúde: um estudo de caso. Revista Científica de Iniciación a la Investigación, v. 3, n. 1, 2018. Disponível em: http://revistacientifica.uaa.edu.py/index.php/rcuaa/article /view/ 425. Acesso em: 23 maio 2019.

SANTOS, A.R. Metodologia científica: a construção do conhecimento. 4. ed. Rio de Janeiro: DP\&A editora, 2001.

Persp. Online: hum \& sociais aplicada., Campos dos Goytacazes, 27 (10) 46-62-2020 seer.perspectivasonline.com.br 
SILVA, C. C. Alimentação e crescimento saudável em escolares. In: BOCCALETTO, Estela Marina Alves; MENDES, Roberto Teixeira (orgs.) In: Alimentação, Atividade Física e Qualidade de Vida dos Escolares do Município de Vinhedo/SP, 2009, p. 15-21. Disponível em: https://www.fef.unicamp.br/fef/sites/uploads/deafa/qvaf/escolares_cap2.pdf

SOCIEDADE BRASILEIRA DE NEUROPSICOPEDAGOGIA - SNBPp (Brasil). Resolução $\mathbf{n}^{\mathbf{0}}$ 03/2014. Código de Ética Técnico-Profissional da Neuropsicopedagogia, Joinville, 30 jul.2014.

SONATI, J. G.. A Alimentação e a saúde do escolar. In: BOCCALETTO, Estela Marina Alves; MENDES, Roberto Teixeira (orgs.). Alimentação, atividade física e qualidade de vida dos escolares do Município de Vinhedo/SP, 2009, p. 31-38. Disponível em: https://www.fef.unicamp.br/fef/sites/uploads/deafa/qvaf/escolares_completo.pdf\#page=31.

Acesso em: 16 nov. 2019. 